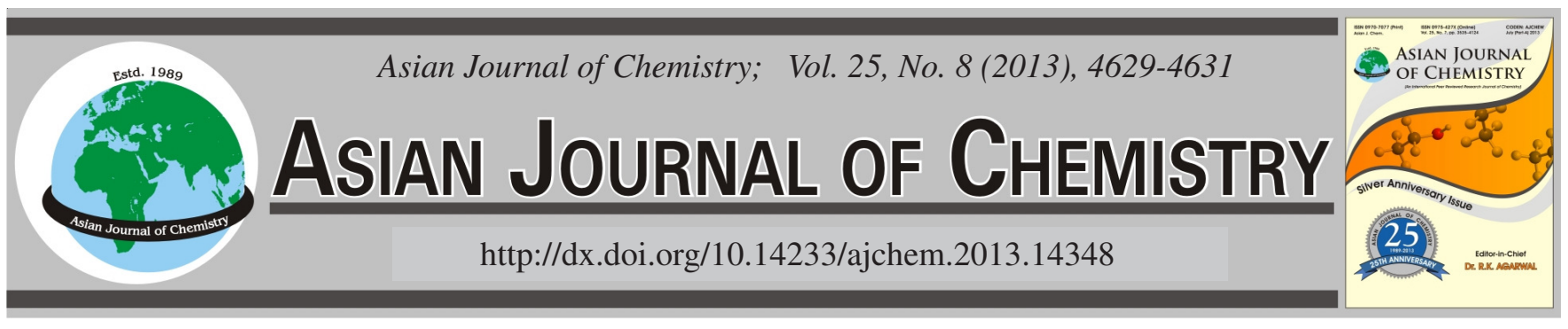

\title{
Synthesis, Crystal Structural and Activities of a New Schiff Base Derived from 2,4,5-Trimethoxybenzaldehyde
}

\author{
Dong-Mei Ye ${ }^{1,2}$, Hou-Li Zhang ${ }^{1}$, Li WAng ${ }^{1}$, QI-Ying YaO ${ }^{1}$, YuAn Lin ${ }^{1, *}$ and Kun Li ${ }^{3, *}$
}

${ }^{1}$ Pharmaceutical College, Dalian Medical University, Liaoning 116044, P.R. China

${ }^{2}$ College of Medicine, Chifeng University, Inner Mongolia 024000, P.R. China

${ }^{3}$ School of Chemistry and Chemical Engineering, Liaoning Normal University, Dalian 116029, P.R. China

*Corresponding authors: Fax/Tel: +86 411 86110409; E-mail: linyuandmu2008@qq.com; dalianlikun@163.com

\begin{abstract}
A new Schiff base, 3,5-dihydroxy- $N^{\prime}$-(2,4,5-trimethoxybenzylidene)benzohydrazide hydrate (DTBH) was synthesized and characterized by elemental analysis and X-ray single crystal diffraction. 3,5-Dihydroxy- $N$ '-(2,4,5-trimethoxybenzylidene)benzohydrazide hydrate crystallized in a monoclinic system, space group $\mathrm{P} 2_{1} / \mathrm{n}$ with $\alpha=11.720(12), \mathrm{b}=10.028(10), \mathrm{c}=14.444(14) \AA, \beta=97.637(10)^{\circ}, \mathrm{Z}=4$, $\mathrm{V}=1683(3) \AA^{3}, \mathrm{D}_{\mathrm{c}}=1.438 \mathrm{~g} / \mathrm{cm}^{3}, \mathrm{~F}(000)=768.0, \mu=0.113$ and $\mathrm{S}=1.028$. The final $\mathrm{R}=0.0512$ and $\mathrm{wR}=0.1230$ for 2093 observed reflections with I $>2 \sigma(\mathrm{I})$. The antibacterial activities, cytotoxicities and effects of 3,5-dihydroxy- $N^{\prime}$-(2,4,5-trimethoxybenzylidene) benzohydrazide hydrate on the contractility of isolated jejunal smooth muscle (IJSM) of rats were evaluated. 3,5-Dihydroxy- $N^{\prime}-(2,4,5-$ trimethoxybenzylidene)benzohydrazide hydrate showed no antibacterial activity. No cytotoxic effects were found on Caco- 2 cell line within $360 \mu \mathrm{M}$. However, it indicated significant inhibitory effect on the contractility of isolated jejunal smooth muscle in a dose dependent manner. The inhibitory effects are related to the activation of $\alpha$ and $\beta$-adrenoceptors.
\end{abstract}

Key Words: Schiff base, Crystal structure, Contractility of jejunal smooth muscle.

\section{INTRODUCTION}

Hydrazones can be synthesized from hydrazide and aldehyde or ketone by using "click chemistry"1 carbonyl chemistry of the "non-aldol" style. They belong to Schiff base compounds containing $\mathrm{AC}=\mathrm{NB}$ structure. Hydrazones are widespread in agriculture, medicine and analytical reagents because of their diverse activities. In recent years, attention has been focusing on their antitumor, catalytical, antifungal, antituberculous, antibacterial and anti-depressant activities ${ }^{2-6}$. In this study, we synthesized a new Schiff base compound, 3,5dihydroxy- $N$ '-(2,4,5-trimethoxy-benzylidene)benzohydrazide hydrate (DTBH) and detected its crystal structure. Its antibacterial activities, cytotoxic effects and effects on the contractility of isolated jejunal smooth muscle (IJSM) were measured.

\section{EXPERIMENTAL}

3,5-Dihydroxy benzoylhydrazine was purchased from J \& K Scientific Ltd. (Beijing, China). 2,4,5-Trimethoxy benzaldehyde and other chemicals were commercially available. Caco- 2 cells were purchased from American type culture collection (ATCC). Five types of bacteria were provided by pharmacognosy lab of Dalian Medical University.
Melting point measurement was executed on a XT4 binocular micromelting point apparatus (Beijing). HW-400S constant temperature smooth muscle trough and BL-420F biology function experiment system were provided by Chengdu Tai Meng Science and Technology Ltd. Co. Sprague-Dawley (SD) Rats (180-220 g) were provided by SPF animal center of Dalian Medical University. The animal protocol was in accordance with the rules of animal care and was approved by the animal protection committee of Dalian Medical University.

3,5-Dihydroxy benzoylhydrazine $(0.1 \mathrm{mmol})$ and 2,4,5trimethoxybenzaldehyde $(0.1 \mathrm{mmol})$ were dissolved in methanol solution $(10 \mathrm{~mL})$. The mixture was stirred at the room temperature to form a clear colourless solution. Yellow blocks were formed after solvent was gradually evaporated over six days at room temperature. Yield was $86.3 \%$ and melting point range was $214-215^{\circ} \mathrm{C}$. The yellow single crystal was detected by using a Bruker SMART APEX CCD diffractometer.

Cytotoxic and antibacterial activities of DTBH were determined by 3-(4,5-dimethyl- thiazol-2-yl)-2,5-diphenyltetrazolium bromide (MTT) method ${ }^{7-9}$. Segments of the proximal jejunum were prepared and the contractility of IJSM was detected according to the reports before ${ }^{10}$. 
The results were dealt with SPSS 16.0 system and expressed as mean \pm S.E.M. Statistical difference between control and DTBH treated group was analyzed by using student's $t$ tests. $\mathrm{P}<0.05$ was considered statistically significant.

\section{RESULTS AND DISCUSSION}

Crystal structure of DTBH: The structure of DTBH was shown in Fig. 1. According to X-ray data, monoclinic crystals were formed from DTBH in space group $\mathrm{P} 2{ }_{1} / \mathrm{n}$. X-ray single crystal structural analysis revealed that DTBH consists of one Schiff base moiety and one lattice methanol molecule. The bond lengths and bond angles were within normal ranges ${ }^{11}$ and comparable to those corresponding in other similar compounds ${ }^{12-14}$. The bond length of 1.275(3) $\AA$ between atoms C(10) and N(2) was similar to those observed in other Schiff bases ${ }^{15,16}$, indicating that it was a double bond. The bond length of C(11)$\mathrm{N}(1), 1.344(3) \AA$, was intermediate between $\mathrm{C}-\mathrm{N}$ and $\mathrm{C}=\mathrm{N}$ bonds due to the conjugation in the molecule. The mean planes of the two benzene rings made a dihedral angle of 13.14(3) ${ }^{\circ}$. As expected, the molecule adopted a trans configuration about the $\mathrm{C}=\mathrm{N}$ double bond. The torsion angles $\mathrm{C}(12)-\mathrm{C}(11)-\mathrm{N}(1)-$ $\mathrm{N}(2), \mathrm{O}(1)-\mathrm{C}(11)-\mathrm{N}(1)-\mathrm{N}(2), \mathrm{C}(6)-\mathrm{C}(10)-\mathrm{N}(2)-\mathrm{N}(1)$ and $\mathrm{C}(10)-\mathrm{N}(2)-\mathrm{N}(1)-\mathrm{C}(11)$ were -176.79(18), 2.4(3), -178.1 (2) and $179.4(2)^{\circ}$, respectively. Intermolecular $\mathrm{O}(7)-\mathrm{H}(7 \mathrm{~b}) \cdots \mathrm{O}(2)$ hydrogen bond was observed in the molecular structure. The lattice water and amino-group and hydroxyl group of the Schiff base in the crystal were linked to the Schiff base moieties through intermolecular $\mathrm{N}-\mathrm{H} \cdots \mathrm{O}, \mathrm{O}-\mathrm{H} \cdots \mathrm{O}$ hydrogen bonds (Table-1, Fig. 2). The DTBH extended further to its final threedimensional network through intermolecular $\mathrm{N}-\mathrm{H} \cdots \mathrm{O}, \mathrm{O}-\mathrm{H} \cdots \mathrm{O}$ hydrogen bonds which interlinked molecules stabilize the structure. The results indicated that DTBH contained one Schiff base moiety and one lattice methanol molecule. This lattice methanol and two phenolic hydroxyl groups linked to the Schiff base moiety through the intermolecular $\mathrm{N}-\mathrm{H} \cdots \mathrm{O}$, $\mathrm{O}-\mathrm{H}$... O hydrogen bonds, which interlinked molecules stabilize the structure.

Pharmacologic activities of DTBH: No cytotoxic effects on Caco- 2 cells were obseved when the concentration of DTBH was below $360 \mu \mathrm{M}$. No antibacterial activities of DTBH were found against the 5 types of bacteria because minimum inhibitory concentration (MIC) of them was over $50 \mathrm{mg} / \mathrm{mL}$. However, as shown in Fig. 3, DTBH inhibited contractility of

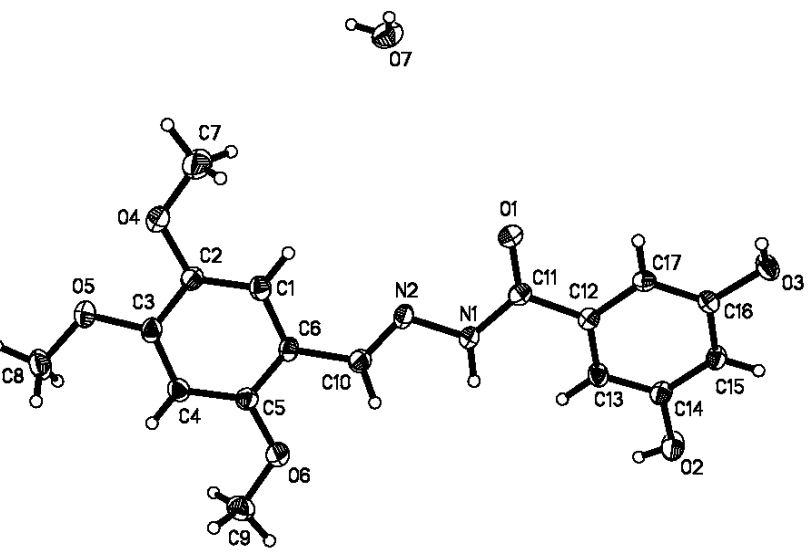

Fig. 1. Structure of the DTBH
TABLE-1

HYDROGEN BONDING DISTANCES $(\AA)$ AND ANGLES $\left({ }^{\circ}\right)$

\begin{tabular}{lcccc}
\hline $\mathrm{D}-\mathrm{H} \cdots \mathrm{A}$ & $\mathrm{d}(\mathrm{D}-\mathrm{H})$ & $\mathrm{d}(\mathrm{H} \cdots \mathrm{A})$ & $\mathrm{d}(\mathrm{D} \cdots \mathrm{A})$ & $<(\mathrm{DHA})$ \\
\hline $\mathrm{O} 2-\mathrm{H} 2 \cdots \mathrm{O} 4^{\mathrm{i}}$ & 0.82 & 2.29 & $2.969(4)$ & 140.9 \\
$\mathrm{O} 2-\mathrm{H} 2 \cdots 5^{\mathrm{i}}$ & 0.82 & 2.23 & $2.921(3)$ & 142.3 \\
$\mathrm{O} 3-\mathrm{H} 3 \cdots \mathrm{O} 1^{\mathrm{ii}}$ & 0.82 & 2.00 & $2.747(3)$ & 150.6 \\
$\mathrm{O} 3-\mathrm{H} 3 \cdots \mathrm{N} 2^{\mathrm{ii}}$ & 0.82 & 2.42 & $3.055(4)$ & 135.6 \\
$\mathrm{~N} 1-\mathrm{H} 1 \cdots \mathrm{O} 7^{\mathrm{ii}}$ & $0.899(10)$ & $2.073(11)$ & $2.967(4)$ & $172(2)$ \\
$\mathrm{O} 7-\mathrm{H} 7 \mathrm{~B} \cdots \mathrm{O} 2^{\mathrm{iii}}$ & $0.860(9)$ & $2.029(12)$ & $2.860(4)$ & $162(2)$ \\
\hline
\end{tabular}

Symmetry codes: (i) $\mathrm{x}+1 / 2,-\mathrm{y}+3 / 2, \mathrm{z}-1 / 2$; (ii) $-\mathrm{x}+3 / 2, \mathrm{y}+1 / 2,-\mathrm{z}+1 / 2$; (iii) $\mathrm{x}-1, \mathrm{y}-\mathrm{z}, \mathrm{z}$

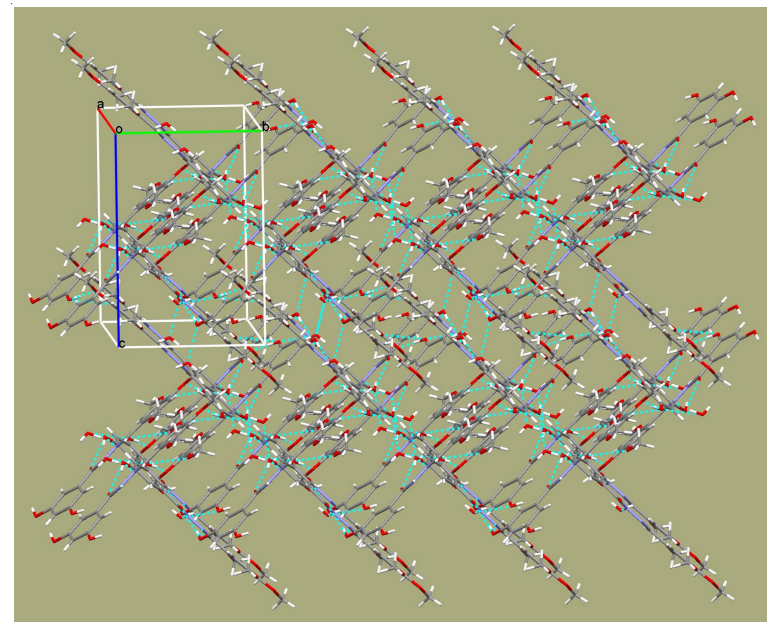

Fig. 2. Crystal packing of DTBH. Intermolecular $\mathrm{O}-\mathrm{H} \cdots \mathrm{O}$ and $\mathrm{N}-\mathrm{H} \cdots \mathrm{O}$ hydrogen bonds were shown as dashed lines. Hydrogen atoms other than those participating in hydrogen bonding were omitted for clarity

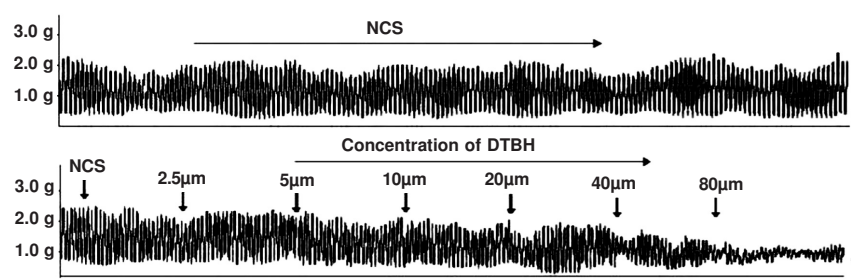

Fig. 3. Representative traces of the effects of DTBH on IJSM in different concentration (NCS: normal contractile state)

IJSM in a dose dependent manner at concentration range of 2.5-80 $\mu \mathrm{M}$. $40 \mu \mathrm{M}$ DTBH was selected to determine its effects on IJSM in the following experiment because it had significant effect but no cytotoxicity. DTBH showed significant inhibitory effects in the different high contractile states which induced by acetylcholine (Ach), high $\mathrm{Ca}^{2+}$ and high $\mathrm{K}^{+}$(Fig. 4, Table-2). $\alpha$ Adrenoceptor antagonist phentolamine and $\beta$ adrenoceptor antagonist propranolol blocked the inhibitory effects of DTBH, respectively, implicating the involvement of $\alpha$ and $\beta$ adrenoceptors in mediating the inhibitory effects of DTBH. Histamine $\mathrm{H}_{1}$ antagonist diphenhydramine and histamine $\mathrm{H}_{2}$ receptor antagonist cimetidine did not influence this inhibitory effects of DTBH (Fig. 4 and Table-2).

\section{Conclusion}

DTBH contained one Schiff base moiety and one lattice methanol molecule. This lattice methanol and two phenolic hydroxyl groups linked to the Schiff base moiety through the intermolecular $\mathrm{N}-\mathrm{H} \cdots \mathrm{O}, \mathrm{O}-\mathrm{H} \cdots \mathrm{O}$ hydrogen bonds, which 

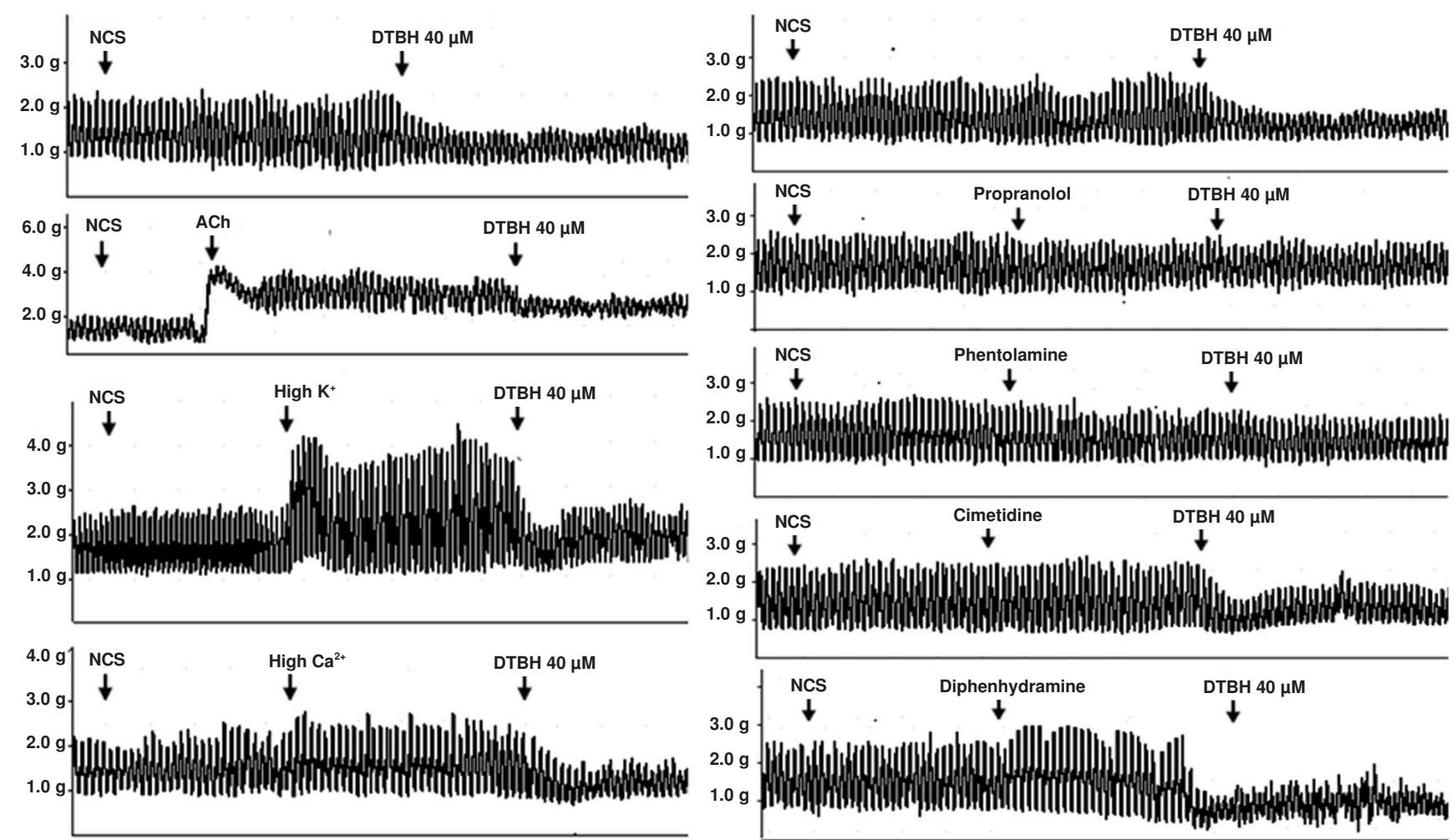

Fig. 4. Representative traces of the effects of DTBH on IJSM in high contractile states and in the presence antagonist

\begin{tabular}{|c|c|c|c|}
\hline \multicolumn{4}{|c|}{$\begin{array}{c}\text { TABLE-2 } \\
\text { EFFECTS OF DTBH ON IJSM IN THE PRESENCE } \\
\text { ANTAGONIST (NORMAL \% mean } \pm \text { S.E.M) }\end{array}$} \\
\hline Agents & $\begin{array}{c}\text { Pre- } \\
\text { treatment* }\end{array}$ & $\begin{array}{c}\text { Post- } \\
\text { treatment* }\end{array}$ & $\begin{array}{c}\text { Number of } \\
\text { cases (n) }\end{array}$ \\
\hline Control & $96.23 \pm 4.60$ & $86.51 \pm 3.66^{\mathrm{a}}$ & 15 \\
\hline Acetylcholine $(2 \mu \mathrm{M})$ & $206.78 \pm 5.52$ & $143.53 \pm 2.18^{\mathrm{a}}$ & 9 \\
\hline $\operatorname{High~Ca}^{2+}(5 \mu \mathrm{M})$ & $105.42 \pm 1.61$ & $92.25 \pm 1.95^{\mathrm{a}}$ & 9 \\
\hline $\operatorname{High}^{+}(5 \mu \mathrm{M})$ & $119.27 \pm 4.22$ & $94.95 \pm 3.52^{\mathrm{a}}$ & 9 \\
\hline Propanolol $(5 \mu \mathrm{M})$ & $96.34 \pm 2.72$ & $94.52 \pm 3.98$ & 11 \\
\hline Phentolamine $(5 \mu \mathrm{M})$ & $97.45 \pm 1.97$ & $95.88 \pm 2.45$ & 11 \\
\hline Cimetidine $(5 \mu \mathrm{M})$ & $99.53 \pm 1.56$ & $90.31 \pm 1.85^{\mathrm{a}}$ & 9 \\
\hline Diphenhydramine $(5 \mu \mathrm{M})$ & $91.47 \pm 3.78$ & $83.33 \pm 2.56^{\mathrm{a}}$ & 9 \\
\hline
\end{tabular}

interlinked molecules stabilize the structure. Though, Schiff bases in their synthesis and antibacterial activities have been carried on in recent years ${ }^{17}$, the antibacterial activities of DTBH were not observed in our assay. It was reported that the zinc and manganese complexes derived from Schiff bases displayed greater antibacterial activities ${ }^{18}$, which indicated that substituent groups may play an important role in antibacterial activities of Schiff bases. In normal contractile state, DTBH inhibited IJSM in a dose range of $2.5-80 \mu \mathrm{M}$. DTBH also significantly decreased the hyper-contractility induced by Ach, high $\mathrm{Ca}^{2+}$ and high $\mathrm{K}^{+}$respectively. The inhibitory effects of DTBH were found to be related to $\alpha$ and $\beta$ receptor, since both $\alpha$ and $\beta$ receptor antagonists abolished the inhibitory effects of DTBH. Whether the inhibitory effects of DTBH on intestinal motility can be utilized in the treatment of intestinal motility disorder, e.g., irritable bowel syndrome (diarrhea) require further study.

\section{ACKNOWLEDGEMENTS}

This study was supported by the National Natural Science Foundation of China (No. 30772601).

\section{REFERENCES}

1. H.C. Kolb, M.G. Finn and K.B. Sharpless, Angew. Chem. Int. Ed, 40, 2004 (2001).

2. A. Abhilasha, Asian J. Chem., 22, 1017 (2010).

3. P. Dandawate, E. Khan, S. Padhye, H. Gaba, S. Sinha, J. Deshpande, S.K. Venkateswara, M. Khetmalas, A. Ahmad and F.H. Sarkar, Bioorg. Med. Chem. Lett., 22, 3104 (2012).

4. D.Q. Long, D.J. Li and W.Q. Cai, Chem. Res. Appl., 19, 1246 (2007).

5. J.X. Hou, L.Y. Chen, X.B. Tang and W.H. Sun, Acta Ploym. Sin., 5, 754 (2004).

6. R. Sevim and S.G. Kucukguzel, Molecules, 12, 1910 (2007)

7. Y.P. Diao, M.T. Zhong, H.L. Zhang, S.S. Huang, X. Liu, C.X. Li, Z.B. Zheng, Y. Lin and M. Huang, Chinese J. Struct. Chem., 11, 1684 (2010).

8. T. Slater, Biochem. Biophys. Acta, 77, 383 (1963).

9. A.A. Van de Loosdrecht, J. Immunol. Methods, 174, 311 (1994).

10. L. Barthó and R.A. Lefebvre, Eur. J. Pharmacol., 259, 101 (1994).

11. F.H. Allen, O. Kennard, D.G. Watson, L. Brammer, A.G. Orpen and R.J. Taylor, Chem. Soc., Perkin Trans. II, S1 (1987).

12. S. Deng, L. Han, S. Huang, H. Zhang, Y. Diao and K. Liu, Acta Cryst., E65, 721 (2009).

13. D.F. Zhang, D.Y. Liu, C.X. Li, S.S. Huang and B.J. Zhang, Acta Cryst., E67, 940 (2011).

14. Z.G. Wang, L.Yuan, L. Zhou and Y. Nan, Acta Cryst., E67, 841 (2011).

15. J.M. Li, J.Z. Li, H.Q. Zhang, J. Li and Y. Zhang, Chinese J. Struct. Chem., 29, 1552 (2010).

16. J. Li, J.Z. Li, J.Q. Li, H.Q. Zhang and J.M. Li, Acta Cryst., E65, 1824 (2009).

17. K. Nehru, P. Athappan and G. Rajagopal, Transition Met. Chem., 26, 652 (2001)

18. X.M. Ma, Y.P. Luo, B.C. Ma and R.D. Yang, J. Lanzhou Med. Coll., 29, 3 (2003). 